\title{
O avesso do centro de tratamento intensivo: a angústia do profissional de saúde diante do enfrentamento da morte
}

The reverse side of the intensive care center: the health professional's anguish in the face of death

El lado inverso del centro de terapia intensiva: la angustia del profesional de salud ante la muerte

Laudy Gabriele Pereira Guimarães ${ }^{1 *}$, Eunes de Castro Milhomem²

\section{RESUMO}

Objetivo: Discutir as duas principais formas de teorização do conceito de angústia segundo Sigmund Freud, com foco em profissionais de saúde que lidam com pacientes em estado grave, tendo como motivação a vivência dentro de um centro de tratamento intensivo (CTI). Metodologia: Narrativa bibliográfica, baseadas na teoria psicanalítica, especificamente nos escritos freudianos, sobre o conceito de angústia, por meio de pesquisa à SciELO, Google Acadêmico e livros-textos de referência sobre o tema. Resultados: $O$ ambiente de um CTI é inegavelmente de confronto, vê-se a luta pela vida dos pacientes, a luta das famílias diante da incerteza e a dos profissionais que se dedicam para salvar vidas. Existe ainda um conflito menos evidente, mas importante para o bom funcionamento deste ambiente: o confronto dos profissionais de saúde com a perspectiva de sua própria finitude. Deparar-se com o final da vida de outrem pode gerar severos questionamentos àqueles que o conheciam, mas quando falamos de profissionais que se capacitaram para postergar este fim e não lograram seus objetivos, este dano pode ser ainda maior. Considerações finais: No caso de profissionais de saúde a projeção da sua própria finitude, da fragilidade do ser, da solidão, potencializados pelas experiências vividas em um CTI, pode ser forte motivador de angústia e recalque como visto na segunda teoria de Freud. Trazer esta questão para o debate e, sobretudo, desenvolver pesquisas a respeito pode ser determinante para uma melhor qualidade de vida destes profissionais e seus pacientes.

Palavras-chave: Angústia, Psicanálise, Centro de Tratamento Intensivo.

\section{ABSTRACT}

Objective: To discuss the two main forms of theorization of the concept of anguish according to Sigmund Freud, focusing on health professionals who deal with patients in a serious condition, having as motivation the experience inside an intensive care center (ICC). Methodology: Bibliographic narrative, based on psychoanalytic theory, specifically in Freudian writings, on the concept of anguish, through research to SciELO, Google Scholar and reference textbooks on the subject. Results: The environment of a ICC is undeniably confrontational, we can see the struggle for the patients 'lives, the families' struggle in the face of uncertainty, and the professionals who are dedicated to saving lives. There is also a less evident conflict, but important for the proper functioning of this environment: the confrontation of health professionals with the perspective of their own finitude. Meeting the end of another's life can generate severe questions to those who knew it, but when we talk about professionals who have been trained to postpone this end and have not achieved their goals, this damage can be even greater. Final considerations: In the case of health professionals, the projection of their own finitude, the fragility of being, of solitude, enhanced by the experiences lived in a ICC, can be a strong motivator of anguish and repression as seen in Freud's second theory. Bringing this issue to the debate and, above all, developing research on it can be decisive for a better quality of life for these professionals and their patients.

Key words: Anguish, Psychoanalysis, Intensive Care Center.

\footnotetext{
${ }^{1}$ Especialista em psicologia hospitalar pelo Instituto Nacional de Infectologia (INI-Fiocruz) e Especialista em psicologia clínico institucional pela Univ. do Estado do Rio de Janeiro. * laudypsicologia2017@hotmail.com ${ }_{2}^{2}$ Membro titular da Comissão de Residência Multiprofissional em saúde do INI-Fiocruz, Rio de janeiro-RJ.
}

SUBMETIDO EM: 2/2019 


\section{RESUMEN}

Objetivo: Discutir las dos principales formas de teorización del concepto de angustia según Sigmund Freud, con foco en profesionales de salud que tratan con pacientes en estado grave, teniendo como motivación la vivencia dentro de un centro de tratamiento intensivo (CTI). Metodología: Narrativa bibliográfica, basada en la teoría psicoanalítica, específicamente en los escritos freudianos, sobre el concepto de angustia, por medio de investigación a SciELO, Google Académico y libros-textos de referencia sobre el tema. Resultados: EI ambiente de un CTI es innegablemente de confrontación, se ve la lucha por la vida de los pacientes, la lucha de las familias ante la incertidumbre y la de los profesionales que se dedican a salvar vidas. También existe un conflicto menos evidente, pero importante para el buen funcionamiento de este ambiente: la confrontación de los profesionales de la salud con la perspectiva de su propia finitud. El encontrarse con el final de la vida de otro puede generar severos cuestionamientos a aquellos que lo conocían, pero cuando hablamos de profesionales que se capacitar para postergar este fin y no lograr sus objetivos, este daño puede ser aún mayor. Consideraciones finales: En el caso de los profesionales de la salud la proyección de su propia finitud, de la fragilidad del ser, de la soledad, potenciados por las experiencias vividas en un CTI, puede ser fuerte motivador de angustia y represión como se ve en la segunda teoría de Freud. Traer esta cuestión para el debate y, sobre todo, desarrollar investigaciones al respecto puede ser determinante para una mejor calidad de vida de estos profesionales y sus pacientes.

Palabras clave: Angustia, Psicoanálisis, Centro de Tratamiento Intensivo.

\section{INTRODUÇÃO}

De acordo com Foucault (2000), o hospital com intervenção terapêutica data do século XVIII, pois somente em 1780 que ele aparece como instrumento destinado a curar mediante a prática de visita e observação. Nem sempre foi um espaço de cura, considerando que na ldade Média, a função dos hospitais era de assistência aos pobres, recolhendo-os para serem assistidos material e espiritualmente. Além da função assistencial e religiosa, o autor ressalta que até meados do século XVII era um local misto de exclusão, onde se destinavam os doentes, os loucos, os devassos e as prostitutas.

Ainda de acordo com o referido autor, o hospital, a princípio, não foi medicalizado, mas buscou-se destituílo dos efeitos nocivos e das desordens que geravam as doenças. Mediante a inserção da intervenção médica e a disciplinarização teve origem o hospital médico. Sendo assim, a clínica passa a ser uma dimensão do hospital e significa a organização do mesmo como lugar de formação, transmissão do saber e cura.

Neste contexto do hospital geral encontra-se o Centro de Tratamento Intensivo (CTI), local onde são direcionados pacientes que precisam de maior cuidado, constante atenção e monitoramento, com risco de morte iminente. Com isso, segundo Camon (1994) algumas alterações psicológicas podem surgir não só no enfermo, mas também nos profissionais de saúde.

Para Rodrigues (2006), quando em contato com pacientes submetidos a uma variedade de intervenção médica, dependendo de aparelhos, imobilizados, entubados e, sobretudo, ao se aproximarem da experiência da morte, os profissionais de saúde podem deparar-se com sua própria finitude. Diante disso, sentimentos como impotência, fracasso e angústia podem surgir.

Em um momento inicial, Freud (1895) considera a angústia uma ligação com a sexualidade, sendo que a excitação sexual escapava sob a forma transformada da mesma. O autor considera importante diferenciar a neurose de angústia da neurastenia e no final de sua primeira teoria compreende a angústia como afeto decorrente do recalcamento e em virtude disso sua condição de produto do mesmo. Já em sua segunda teoria, Freud define angústia como um afeto anterior e causador do recalque, considerando o "eu" como fonte.

Outro conceito tratado será o de desamparo fundamental, que tem relevante importância para refletir sobre essa condição que remete o profissional a sua própria dependência e fragilidade ao se deparar com a gravidade do quadro clínico dos pacientes, sua total dependência e risco de morte.

Diante disso, esta pesquisa teórica propõe discutir sobre a temática da angústia nos escritos freudianos, visando à compreensão da sua gênese e suas possíveis relações com os sentimentos vivenciados pela 
equipe de saúde do CTI. Trata-se de pesquisa de natureza teórica, visando discutir os dados recolhidos através de levantamento bibliográficos, utilizando livros e artigos científicos, os sobre o tema abordado, ampliando o levantamento com a utilização de materiais científicos virtuais, acessados através do Google Acadêmico e do Scielo, tendo como detectores de busca as palavras angústia, psicanálise e CTI.

Para iniciar o trabalho, serão apresentadas algumas definições sobre CTI e os sentimentos que são despertados nos profissionais de saúde que trabalham nesse espaço e posteriormente as teorias de Freud em relação à angústia. A partir destas considerações, o trabalho irá analisar, utilizando literatura já publicada, o conceito de angústia e considerações sobre o desamparo fundamental na visão da psicanálise.

\section{REVISÃO BIBLIOGRÁFICA}

\section{Cenário do CTI e seus atores}

O Centro de Tratamento Intensivo $(\mathrm{CTI})^{3}$ é um setor do hospital onde são realizados atendimentos e cuidados ininterruptos, inúmeros procedimentos e monitoramento de pacientes onde o estado clínico exige atenção continuada. Conforme definido por Rodrigues (2006), o CTI é uma unidade do hospital onde se encontram recursos materiais e humanos necessários para um atendimento adequado aos pacientes, cujo estado clínico exige cuidados médicos especializados e constantes. $O$ autor ressalta que o objetivo principal é o restabelecimento do funcionamento do sistema orgânico nos doentes graves, "até que a patologia que motivou a internação seja adequadamente compensada ou até que os parâmetros fisiológicos atinjam níveis aceitáveis". (op. cit. p.3)

Apesar de ser um ambiente que recebe pacientes com diagnóstico grave, que requerem cuidados ininterruptos e técnicas especializadas, no CTI o enfermo também pode possuir um prognóstico favorável no decorrer do tratamento, sendo importante ter um olhar biopsicossocial desse paciente e o considerar como um indivíduo que tem uma história familiar, pessoal e social, todavia não se abandona a importância do restabelecimento do funcionamento orgânico como um fator fundamental a ser atingido.

Assim destacamos a consideração de Rodrigues (2006):

Nos dias atuais, as UTIs existentes, de modo geral, são locais onde se internam doentes graves que ainda têm um prognóstico favorável para viver. Nesse local, são atendidos casos de pessoas que se encontram em uma situação limite (entre a vida e a morte) e necessitam de recursos técnicos e humanos especializados para sua recuperação. (op. cit. p. 4)

Segundo Di Biaggi (2002), a rotina de um CTI é de constante apreensão, com profissionais revezando-se diariamente no monitoramento de aparelhos e alertas a qualquer manifestação clínica dos pacientes. A este cenário acrescentam-se pacientes que não raro estão entubados, sedados e/ou imobilizados. Diante disso, faz-se necessário o uso de critérios técnicos específicos para a admissão do enfermo em um CTI.

Ainda segundo o autor, em seu trabalho sobre a relação médico-família em CTI, afirma que existem critérios para a admissão de pacientes neste espaço, tais como: pacientes que necessitam de tratamento intensivo, que possuem alto risco de se tornarem gravemente enfermos, e pacientes com pequena probabilidade de sobrevida apesar dos recursos disponíveis nesse espaço.

Logo, no CTI é inegável a preocupação acentuada da equipe de saúde quanto à reversão do quadro orgânico, dos procedimentos utilizados e com o perfil dos pacientes que chegam ao local, já que em alguns momentos a demanda ultrapassa a quantidade de leitos.

Camon (1994) apud Rodrigues (2006) ao descrever sobre algumas características do CTI, afirma que vários fatores psicológicos contribuem de maneira grave na enfermidade que a pessoa possui. São eles: As situações de morte iminente, a rotina de trabalho, a dimensão individual do sofrimento da pessoa internada como a dor, o medo, a ansiedade e o isolamento do mundo.

${ }^{3} \mathrm{CTI}$ - Apesar de diferentes autores preferirem usar o termo UTI ao longo do trabalho utilizaremos CTI. 
Portanto, podemos nos interrogar se esses fatores não produzem alterações emocionais no profissional de saúde que lida diretamente com o sofrimento destes pacientes.

Rodrigues (2006) em seu trabalho sobre a atuação do psicólogo Hospitalar na UTI relata que defrontar-se com pacientes imobilizados, em aparelhos, chorando, além de outras situações constrangedoras, não é algo fácil e traz dificuldades para os profissionais.

Segundo o autor, "cuidar de alguém e, efetivamente, aproximar-se dessa pessoa, pode fazer com que da experiência da morte do próximo, surja à consciência do que seja morrer". (op. cit. p.6) Ou seja, remete à própria finitude do profissional de saúde. Sendo assim, podemos depreender a angústia vivenciada por estes profissionais que tratam outros humanos que estão diante do risco de morte.

Surge então como questão o entendimento sobre este sentimento que invade os profissionais de saúde. Logo, tomando por base a teoria psicanalítica da angústia, buscaremos entender a dinâmica desses afetos.

\section{Conceito freudiano de angústia}

Freud (1894), ainda sob a influência de estudos neurológicos, no decorrer da investigação das neuroses 'atuais' se defronta em um primeiro momento com a questão da angústia concluindo que a excitação acumulada, excitação esta, referente à descarga sexual, escapava sob a forma de angústia.

Ao interrogar sobre a origem da angústia, Freud ainda em 1894 faz uma relação entre a mesma e a sexualidade nos pacientes neuróticos: "Como se origina a angústia? Tudo o que sei a respeito é o seguinte: logo se tornou claro que a angústia de meus pacientes neuróticos tinha muito a ver com a sexualidade".

Assim, em 1895, encontramos no texto freudiano a relação entre a abstinência sexual e a angústia, ocorrendo devido ao acúmulo de tensão sexual. Com isso, volta a questionar-se sobre a existência de fatores psicológicos associados a angustia nos casos clínicos de neuroses fóbicas e obsessivas.

O autor observa que nas psiconeuroses, a razão do acúmulo de excitação não descarregada era psicológica, ou seja, se dava pelo recalque onde a excitação acumulada (ou libido ${ }^{4}$ ) era transformada diretamente em angústia, sendo a mesma, o que surgiria como uma transformação direta dessa tensão.

Segundo Celes (1995), para Freud a angústia surge por mudança da tensão sexual acumulada e deve-se a uma acumulação física de excitação. Trata-se de uma transformação direta da libido de angústia. Para tentar esclarecer melhor esse processo, em seus primeiros trabalhos acerca do tema, Freud destaca a necessidade de fazer uma diferenciação entre neurose de angustia e neurastenia.

Em 1895, Freud depara-se com a necessidade de diferenciar a neurastenia da neurose de angústia sendo a última tomada em seus trabalhos como modelo para a primeira teoria sobre a angústia. A primeira, segundo o autor, decorre de um mau funcionamento sexual, incapaz de resolver de forma adequada a descarga da tensão sexual física que apresenta um extenso repertório de sintomas como a fadiga física, cefaleia, prisão de ventre etc. Já a neurose de angustia é o produto da tensão sexual física que não foi psiquicamente ligada. Esta energia livre que não é descarregada pode ocasionar inúmeras manifestações que se agrupam em torno de um sintoma principal: a angústia. O quadro clínico desta neurose se caracteriza por irritabilidade geral, vertigem, sudorese, taquicardia etc.

Para Celes (1995), no decorrer da primeira teoria de Freud a angústia vem como um afeto que incide posteriormente como produto do recalque, ou seja, "a angústia é paradoxalmente efeito de uma ação que obedece ao princípio do prazer".

Apesar dessas investigações, seu questionamento sobre a angústia já é encontrado em 1897 em sua carta a Fliess onde Freud observa que precisava considerar a libido e o que causa a angústia como fatores separados.

4 "Força quantitativamente variável que poderia servir de medida do processo e das transformações que ocorrem no campo da excitação sexual. Seria uma energia especial que se deve supor subjacente aos processos mentais em geral' (Lopes 2011 apud Freud p.272).

REAS/EJCH | Vol. Sup. 22 | e750 | DOI: https://doi.org/10.25248/reas.e750.2019 Página 4 de 7 
Em 1926, ao estabelecer sua segunda teoria sobre a angústia, não considera mais a mesma como libido transformadora, mas como uma reação sobre um modelo específico a situações de perigo, destacando que a neurose de angústia o surgimento da mesma era uma reação à uma situação traumática.

Freud ainda utilizando a conceituação de neuroses atuais, traz a compreensão da mudança da libido em angústia. Assim, estabelece na histeria de angústia a participação psíquica sob dois aspectos: $O$ primeiro refere-se à constituição da angústia como consequência do recalque, ou seja, mudança da tensão sexual acumulada devido a seu impedimento de satisfação, e no segundo, pontua o trabalho psíquico de religação da angústia liberada, o que determina os sintomas característicos das fobias e inibições, por exemplo.

Com isto, Freud (1926) apresenta sua segunda teoria sobre a angústia. Nela, a angústia não é mais entendida como mudança direta da libido e um afeto posterior ao recalque, mas sim como reação a determinada situação ou acontecimento entendida como situação de perigo, e considerada um afeto anterior e causador do recalque. $O$ autor traz uma distinção entre a angústia como reação direta e automática a um trauma e a angústia como um sinal do perigo do retorno dos fatores que geraram a situação traumática:

Seguindo essa sequência, angústia - perigo - desamparo (trauma), podemos agora resumir o que se disse. Uma situação de perigo é uma situação reconhecida, lembrada e esperada de desamparo. A angústia é a reação original ao desamparo no trauma, sendo reproduzida depois da situação de perigo como um sinal em busca de ajuda. (op. cit. p.161)

Com isso, na visão de Barbosa (2008), parece necessário preservar duas modalidades distintas da angústia em Freud. A automática relacionada à situação traumática que revela a experiência de desamparo por parte do eu, e a angústia como um sinal para o eu se defender, relacionada às situações de perigo.

Para Celes (1995), a proposta da teoria de angústia freudiana se refere a uma angústia automática que decorre de uma situação traumática, situando-a na experiência de desamparo por parte do eu diante de um acúmulo de excitação. A angústia como um sinal é a resposta do eu à ameaça da ocorrência de uma situação traumática, onde esta ameaça constitui uma situação de perigo. Diante disto, se a fonte da angustia não é mais a libido, a função de reação às situações vividas como perigo é dada ao eu, sendo este a sede da angústia. Pensando nestas situações de perigo e ameaça ao eu, o desamparo pode emergir como um fator presente ligado à angústia.

Ainda encontramos em Rocha (1999) a discussão sobre a reformulação da teoria da angústia ressaltando sua íntima relação com o desamparo, constituindo com isso alguns aspectos substanciais: primeiro Freud repensou a natureza da angústia, fazendo do trauma do nascimento uma Urangst, isto é, uma angústia originária que se tornou arquetípica das demais situações de angústia; em seguida, redefiniu na teoria de angústia a função da mesma, introduzindo no eu a angústia-sinal como defesa contra a originária angústia gerada pelo desamparo.

Assim, Freud (1926) repensa a natureza da angústia descobrindo no desamparo primordial do nascimento a angústia na sua forma originária. Ela se repete nas diversas formas de angústia de separação que nos acompanham do nascimento à morte.

\section{O não possível de simbolizar}

Tratando-se de uma situação hospitalar, sobretudo em CTI, sentimento de impotência e incompletude do profissional de saúde, principalmente quando submetidos à perda de pacientes, pode desencadear desamparo e consequentemente angústia.

Para Dockhorn, Macedo e Werlang (2007), o desamparo é facilmente observado quando na perspectiva do paciente "A concepção de desamparo é introduzida na obra freudiana a partir da incapacidade do bebê de sobreviver por suas próprias forças, sem a ajuda de um outro (objeto externo cuidador)". (op. cit. p.9), entretanto pode-se notar que o profissional de saúde quando em posição de responsável pela manutenção de pacientes em estado crítico se deparam com sua própria finitude, podendo se sentir sem recursos, sem proteção, sem amparo.

REAS/EJCH | Vol. Sup. 22 | e750 | DOI: https://doi.org/10.25248/reas.e750.2019 Página 5 de 7 
Em situações onde o paciente permanece sozinho (sem parentes ou amigos) durante todo tratamento, essa angústia do profissional de saúde mostra-se mais evidente. "Serei eu o próximo a morrer sozinho?".

Sendo o sentimento de desamparo uma vivência do traumático que traz questionamentos ao profissional, Nogueira Lima (2000) afirma que Lacan aborda sobre angústia como algo da ordem do real ${ }^{5}$, que não se pode simbolizar e explicar "é um afeto que não engana sobre sua causa, e esta é real: algo irredutível que se opõe ao significante" Com isso pode-se pensar que sendo a angústia da ordem do real, esse sentimento é algo que não se consegue expressar em palavras, é o não possível de simbolizar.

Evidenciando a angústia como algo que invade os profissionais de saúde em CTI, Otonni (2005) afirma que tais profissionais têm dificuldade para aceitar a finitude dos pacientes por depararem-se com sua fragilidade e efemeridade da vida. Este fato pode acabar interferindo na assistência prestada aos enfermos, pois fazem emergir alguns sentimentos como a frustração, a sensação de fracasso, a impotência e a incapacidade.

Podemos considerar a partir dos estudos de Otonni (2005) que apesar de serem questões que fazem parte da vida, a equipe de saúde depara-se com sua impotência diante da perda de um paciente ou mesmo de quadros irreversíveis, já que esses profissionais durante sua formação foram treinados para salvar vidas, reverter quadros graves e descobrir novas possibilidades. Ocorrendo com a morte ou a irreversibilidade da situação do paciente, sentimento de perda, ineficácia e angústia, acarretando assim dificuldades no enfrentamento da mesma com possíveis consequências para o profissional de saúde fora do ambiente hospitalar.

\section{CONSIDERAÇÕES FINAIS}

O ambiente de um CTI é inegavelmente de confronto, vê-se a luta pela vida dos pacientes, a luta das famílias diante da incerteza e a dos profissionais que se dedicam para salvar vidas. Existe ainda um conflito menos evidente, mas importante para o bom funcionamento deste ambiente: o confronto dos profissionais de saúde com a perspectiva de sua própria finitude.

Deparar-se com o final da vida de outrem pode gerar severos questionamentos àqueles que o conheciam, mas quando falamos de profissionais que se capacitaram para postergar este fim e não lograram seus objetivos, este dano pode ser ainda maior.

No caso de profissionais de saúde a projeção da sua própria finitude, da fragilidade do ser, da solidão, potencializados pelas experiências vividas em um CTI, pode ser forte motivador de angústia e recalque como visto na segunda teoria de Freud.

Trazer esta questão para o debate e, sobretudo, desenvolver pesquisas a respeito pode ser determinante para uma melhor qualidade de vida destes profissionais e seus pacientes.

\section{REFERÊNCIAS}

1. ANGERAMI-CAMON, W. A. (org.), Psicologia Hospitalar: Teoria e Prática. São Paulo: Pioneira, 1994.

2. BARBOSA, Ana Carolina Andrade. A angústia como incidência clínica do irrepresentável da pulsão: desamparo, trauma e repetição. In: Revista Reverso, Belo Horizonte, ano 30, n. 56, p. 41-60, 2008.

3. CELES, Luiz Augusto Monnerat. A angústia e suas relações com o Princípio de Prazer. In: Percurso - Revista de Psicanálise, São Paulo, vol. 7, n. 14, pp. 1995.

4. DI BIAGGI, T. M. Relação Médico-família em UTI: a visão do médico intensivista. In: Dissertação de Mestrado Pontifícia Universidade Católica de São Paulo, São Paulo, 2002.

${ }^{5}$ Real- "É o registro psíquico que não deve ser confundido com a noção corrente de realidade. O real é o impossível, aquilo que não pode ser simbolizado e que permanece impenetrável no sujeito" (BRAGA, 1999, p. 2) 
5. DOCKHORN, C. N. B. F., MACEDO, M. M. K. \& WERLANG, B. G. Desamparo e dor psíquica na escuta da Psicanálise. In: Revista Barbarói, 27 (2), 25-42. 2007.

6. FOUCAULT M. Microfísica do Poder. 15ª ed. Rio de Janeiro: GRAAL, 2000.

7. FREUD, S. Rascunho E: Como se origina a ansiedade. In: Edição Standard Brasileira das Obras Psicológicas Completas de Sigmund Freud, Vol. 3. Rio de Janeiro: Imago, 1996. (Originalmente publicado em 1894).

8. FREUD, S. Sobre os fundamentos para destacar da neurastenia uma síndrome denominada neurose de angústia. In: Edição Standard Brasileira das Obras Psicológicas Completas de Sigmund Freud. Vol. 3. Rio de Janeiro: Imago, 1996. (Originalmente publicado em 1895).

9. FREUD, S. Inibições, sintomas e ansiedade. In: Edição Standard Brasileira das Obras Psicológicas Completas de Sigmund Freud, Vol. 20. Rio de Janeiro: Imago, 1996. (Originalmente publicado em 1926[1925]).

10. LACAN, Jacques, O Seminário X, 1962-1963, lição I, 14 de novembro de 1962, a lição XI, 20 de fevereiro de 1963, tradução do CEF-Recife, exemplar mimeo.

11. OTTONI, M.B.H. O Paciente terminal adulto e os medos do morrer. In: Serviço de Psicologia hospitalar, Santa Casa de São Paulo, São Paulo, 2005.

12. ROCHA, Zeferino. Desamparo e metapsicologia. In: Síntese - Revista de Filosofia, Belo Horizonte, v. 26, n. 08, p. 331-346, 1999.

13. RODRIGUES, Kátia Regina Beal. A atuação do psicólogo hospitalar na unidade de terapia intensiva, In: Relatório de estágio supervisionado em Psicologia da Saúde e Hospitalar, Hospital Presbiteriano Dr. Gordon, Rio Verde, GO, 2006. 